\title{
Post-polypectomy colonoscopy surveillance: European Society of Gastrointestinal Endoscopy (ESGE) Guideline - Update 2020
}

\section{(马) ESGE}

Authors

Cesare Hassan ${ }^{1}$, Giulio Antonelli ${ }^{1}$, Jean-Marc Dumonceau ${ }^{2}$, Jaroslaw Regula ${ }^{3}$, Michael Bretthauer ${ }^{4}$, Stanislas Chaussade $^{5}$, Evelien Dekker ${ }^{6}$, Monika Ferlitsch ${ }^{7}$, Antonio Gimeno-Garcia ${ }^{8}$, Rodrigo Jover ${ }^{9}$, Mette Kalager $^{4}$, Maria Pellisé ${ }^{10}$, Christian Pox ${ }^{11}$, Luigi Ricciardiello ${ }^{12}$, Matthew Rutter ${ }^{13}$, Lise Mørkved Helsingen ${ }^{4}$, Arne Bleijenberg ${ }^{6}$, Carlo Senore $^{14}$, Jeanin E. van Hooft ${ }^{6}$, Mario Dinis-Ribeiro ${ }^{15}$, Enrique Quintero ${ }^{8}$

Institutions

1 Gastroenterology Unit, Nuovo Regina Margherita Hospital, Rome, Italy

2 Gastroenterology Service, Hôpital Civil Marie Curie, Charleroi, Belgium

3 Centre of Postgraduate Medical Education and Maria Sklodowska-Curie Memorial Cancer Centre, Institute of Oncology, Warsaw, Poland

4 Clinical Effectiveness Research Group, Oslo University Hospital and University of Oslo, Norway

5 Gastroenterology and Endoscopy Unit, Faculté de Médecine, Hôpital Cochin, Assistance PubliqueHôpitaux de Paris (AP-HP), Université Paris Descartes, France

6 Department of Gastroenterology and Hepatology, Amsterdam University Medical Centers, University of Amsterdam, The Netherlands

7 Department of Internal Medicine III, Division of Gastroenterology and Hepatology, Medical University Vienna, and Quality Assurance Working Group, Austrian Society for Gastroenterology and Hepatology, Vienna, Austria

8 Gastroenterology Department, Hospital Universitario de Canarias, Instituto Universitario de Tecnologías Biomédicas (ITB) \& Centro de Investigación Biomédica de Canarias (CIBICAN), Universidad de La Laguna, Tenerife, Spain

9 Service of Digestive Medicine, Alicante Institute for Health and Biomedical Research (ISABIAL Foundation), Alicante, Spain

10 Gastroenterology Department, Endoscopy Unit, ICMDiM, Hospital Clinic, CIBEREHD, IDIBAPS, University of Barcelona, Catalonia, Spain

11 Department of Medicine, St. Joseph Stift, Bremen, Germany

12 Department of Medical and Surgical Sciences, S. Orsola-Malpighi Hospital, Bologna, Italy
13 Gastroenterology, University Hospital of North Tees, Stockton-on-Tees, UK and Northern Institute for Cancer Research, Newcastle University, Newcastle upon Tyne, UK

14 Epidemiology and screening Unit - CPO, Città della Salute e della Scienza University Hospital, Turin, Italy

15 CIDES/CINTESIS, Faculty of Medicine, University of Porto, Porto, Portugal

Bibliography

DOI https://doi.org/10.1055/a-1185-3109

Published online: 22.6.2020 | Endoscopy 2020; 52: 687-700

(c) Georg Thieme Verlag KG Stuttgart · New York

ISSN 0013-726X

Corresponding author

C. Hassan, MD, Nuovo Regina Margherita Hospital, Via

E. Morosini 53, 00159, Rome, Italy

Fax: +39-06-58446608

cesareh@hotmail.com

丹 Appendix 1s-3s

Online content viewable at:

https://doi.org/10.1055/a-1185-3109

\section{MAIN RECOMMENDATIONS}

The following recommendations for post-polypectomy colonoscopic surveillance apply to all patients who had one or more polyps that were completely removed during a high quality baseline colonoscopy.

1 ESGE recommends that patients with complete removal of $1-4<10 \mathrm{~mm}$ adenomas with low grade dysplasia, irrespective of villous components, or any serrated polyp $<10 \mathrm{~mm}$ without dysplasia, do not require endoscopic surveillance and should be returned to screening.

Strong recommendation, moderate quality evidence.

If organized screening is not available, repetition of colonoscopy 10 years after the index procedure is recommended. Strong recommendation, moderate quality evidence. 
2 ESGE recommends surveillance colonoscopy after 3 years for patients with complete removal of at least 1 adenoma $\geq 10 \mathrm{~mm}$ or with high grade dysplasia, or $\geq 5$ adenomas, or any serrated polyp $\geq 10 \mathrm{~mm}$ or with dysplasia.

Strong recommendation, moderate quality evidence.

3 ESGE recommends a 3-6-month early repeat colonoscopy following piecemeal endoscopic resection of polyps $\geq 20 \mathrm{~mm}$.

Strong recommendation, moderate quality evidence.

A first surveillance colonoscopy 12 months after the repeat colonoscopy is recommended to detect late recurrence. Strong recommendation, high quality evidence.
4 If no polyps requiring surveillance are detected at the first surveillance colonoscopy, ESGE suggests to perform a second surveillance colonoscopy after 5 years.

Weak recommendation, low quality evidence.

After that, if no polyps requiring surveillance are detected, patients can be returned to screening.

5 ESGE suggests that, if polyps requiring surveillance are detected at first or subsequent surveillance examinations, surveillance colonoscopy may be performed at 3 years. Weak recommendation, low quality evidence.

A flowchart showing the recommended surveillance intervals is provided ( $\mathrm{Fig} .1$ )

\section{SOURCE AND SCOPE}

This Guideline is an official statement of the European Society of Gastrointestinal Endoscopy (ESGE). It is an update of the previously published 2013 Guideline addressing the role of post-polypectomy colonoscopy surveillance.

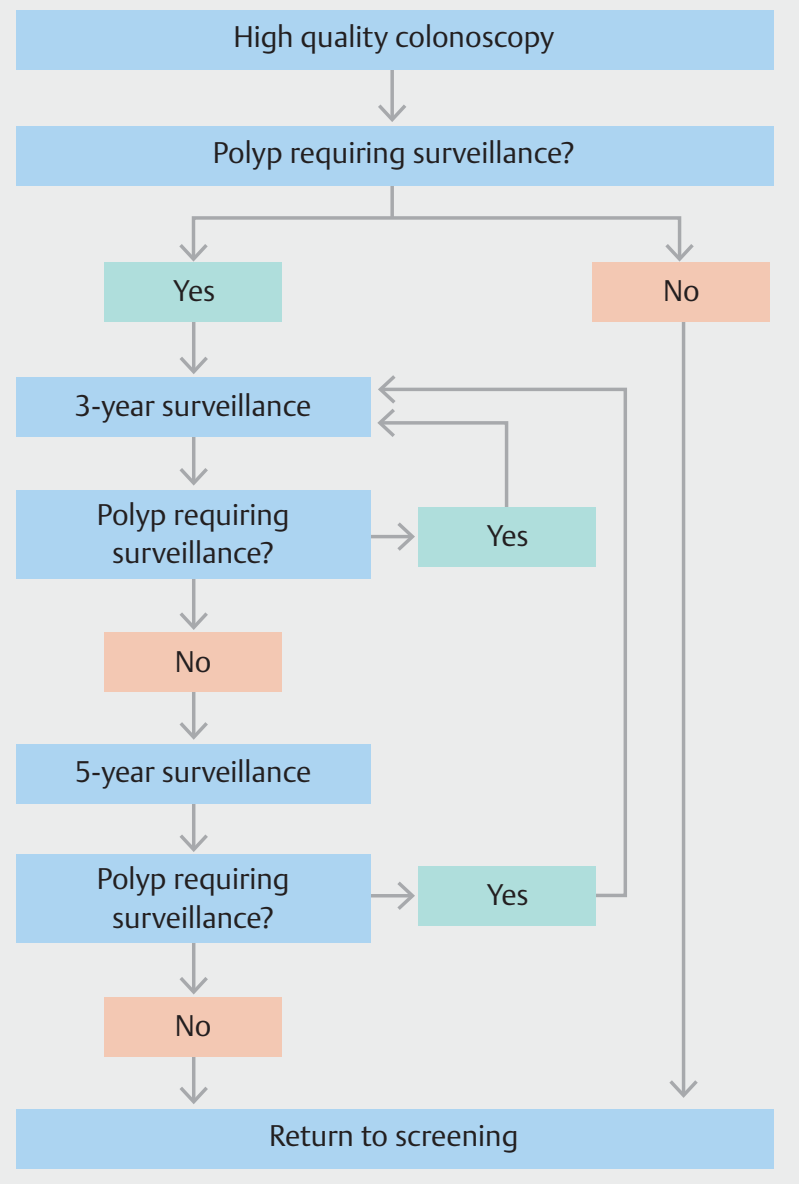

- Fig. 1 Colonoscopy surveillance intervals following polypectomy.

\section{Introduction}

This Guideline represents an update of the Guideline on postpolypectomy endoscopic surveillance published by the European Society of Gastrointestinal Endoscopy (ESGE) in 2013 [1].

Previous recommendations were primarily based on estimates of the risk of metachronous advanced neoplasia (advanced adenoma or colorectal cancer [CRC]) according to the endoscopic and histological features at the baseline colonoscopy that represented most of the available evidence.

According to the Grading of Recommendations Assessment, Development and Evaluation (GRADE) methodology adopted for ESGE guidelines [2,3], a hierarchy across outcomes must be created, and the main recommendations should be based on

$\begin{array}{ll}\text { ABBREVIATIONS } \\ \text { ADR } & \text { adenoma detection rate } \\ \text { ARR } & \text { adjusted rate ratio } \\ \text { CI } & \text { confidence interval } \\ \text { CRC } & \text { colorectal cancer } \\ \text { EMR } & \text { endoscopic mucosal resection } \\ \text { ESGE } & \text { European Society of Gastrointestinal Endoscopy } \\ \text { FIT } & \text { fecal immunochemical test } \\ \text { FOBT } & \text { fecal occult blood test } \\ \text { GRADE } & \text { Grading of Recommendations Assessment, } \\ & \text { Development and Evaluation } \\ \text { Hb } & \text { hemoglobin } \\ \text { HGD } & \text { high grade dysplasia } \\ \text { HR } & \text { hazard ratio } \\ \text { LST } & \text { laterally spreading tumor } \\ \text { OR } & \text { odds ratio } \\ \text { PICO } & \text { population, intervention, comparison/control, } \\ & \text { outcome } \\ \text { RCT } & \text { randomized controlled trial } \\ \text { RR } & \text { risk ratio } \\ \text { SD } & \text { standard deviation } \\ \text { SERT } & \text { Sydney EMR Recurrence Tool } \\ \text { SIR } & \text { standardized incidence ratio } \\ \text { SSL } & \text { sessile serrated lesion } \\ & \end{array}$


the estimates of benefit and risk (burden) of the most clinically relevant outcomes. In this regard, risk of CRC incidence and mortality was ranked as a more relevant outcome than the risk of metachronous advanced neoplasia for estimating the benefit of post-polypectomy surveillance. Of note, this applies both to the stratification of baseline risk at index colonoscopy and to the assessment of the efficacy of endoscopic surveillance.

Recently, a series of cohort studies assessed the postpolypectomy risk of CRC incidence/mortality with and without endoscopic surveillance. The overall long-term CRC risk following polypectomy appeared to be similar or slightly higher than for the general population or for patients without adenomas. In detail, a $2 \%$ absolute long-term CRC risk for post-polypectomy patients without surveillance has been shown, ranging between $1.1 \%$ and $2.9 \%$ according to the baseline risk stratification [4]. These estimates were confirmed in a surveillance setting, with a 10-year CRC incidence risk between $0.44 \%$ and $1.24 \%$, and mortality risk between $0.03 \%$ and $0.25 \%$ [5]. In addition, the efficacy of surveillance for patients at high risk of CRC appeared to be less than 1\% [4], while it was ineffective in patients at lower risk (Table 1s; see Appendix 1s, online-only Supplementary Material). Of note, these estimates are much lower than the $3 \%$ long-term CRC risk required in one guideline for recommending CRC screening [6]. Overall, this new evidence supports a very conservative and selective approach to postpolypectomy surveillance.

As compared with the 2013 ESGE Guideline, the roles of some endoscopic or histological risk factors have been questioned. In particular, the risks of multiplicity or of villous histology regarding CRC in the long-term seem to be low or negligible, hence the relevance of these factors in stratification of the baseline risk is now questioned $[4,7,8]$. Furthermore, additional evidence based on long-term risk of CRC incidence and mortality has become available with regard to serrated polyps, strengthening the previous recommendations [9-11].

The efficacy of endoscopic surveillance must be weighed against safety and burden. Diagnostic colonoscopy is considered to entail a very low risk of adverse events with estimates of $0.05 \%, 0.25 \%$, and $0.003 \%$ for perforation, bleeding, and death, respectively [12]. However, these risks may increase in patients with co-morbidities or older age [13] (Table 2s). In addition, unfavorable psychological effects of surveillance have also been shown, at least in patients with high risk adenomas [14]. Colonoscopy capacity is limited and is mainly expended in population-based organized CRC screening programs, as either work-up of a positive fecal-based stool test or primary screening intervention. The very high prevalence of adenomas in the era of quality assurance and high definition colonoscopy - up to over $70 \%$ of the screening population [15] - mandates a conservative surveillance policy in order to avoid waste of resources [14, 16-18] (Table 3s).

The primary aim of this ESGE update is to incorporate new evidence into the clinical recommendations to be adopted in routine and specific scenarios.

\section{Methods}

ESGE commissioned the update of this Guideline and appointed a guideline leader (C.H.), who invited the listed authors to participate in the project development. The key questions were prepared by the coordinating team (E.Q., J.M.D., J.R.) using PICO methodology (population, intervention, comparison/control, outcome) [19] and were then approved by the other members. The coordinating team formed task force subgroups, based on the statements of the 2013 guideline, each with its own leader, and divided the key topics among these task forces (Appendix 2s) with a specific focus on the update of literature and revision of the statements.

Recent ESGE Guidelines have addressed endoscopic surveillance after endoscopic or surgical resection of invasive carcino$\mathrm{ma} /$ malignant polyp [20] and of patients with hereditary syndromes or with polyposis syndromes [21,22], and these topics are not addressed in the present Guideline.

The work included telephone conferences, a face to face meeting and online discussions.

The task forces conducted a literature search using Medline (via Pubmed) and the Cochrane Central Register of Controlled Trials up to October 2019. New evidence on each key question was summarized in tables using the GRADE system [3] (Appendix 3s). Grading depends on the balance between the benefits and risk or burden of any health intervention [23]. Further details on guideline development have been reported elsewhere [2].

The results of the search were presented to all the members of the task forces during a meeting in Barcelona on October 19th, 2019. After this meeting drafts were made by the leaders of each task force and distributed between the task force members for revision and online discussion. Statements were created by consensus.

In December 2019, a draft prepared by C.H., G.A. and the leaders of all the task forces was sent to all group members. After agreement of all members, the manuscript was reviewed by two external reviewers and was sent for further comments to the ESGE national societies and individual members. After this, the manuscript was submitted to the journal Endoscopy for publication. The final revised manuscript was agreed upon by all the authors.

This Guideline was issued in 2020 and will be considered for update in 2025. Any interim updates will be noted on the ESGE website: http://www.esge.com/esge-guidelines.html.

\section{Evidence and Statements}

For this update, we decided to use the term "polyp" instead of "lesion" or "neoplasia" as the latter two terms can have overly negative connotations for both medical and nonmedical audiences. For similar reasons, we abandoned the terms "high risk" and "low risk" when referring to patients or polyps, replacing them with "need" or "no need" of surveillance. 


\section{Quality of the baseline colonoscopy}

\section{RECOMMENDATION}

2020 statement

The following recommendations for post-polypectomy colonoscopic surveillance apply to all patients who had one or more polyps that were completely removed during a high quality baseline colonoscopy.

Strong recommendation, moderate quality evidence.

\section{3 statement}

The following recommendations for post-polypectomy endoscopic surveillance should only be applied after a high quality baseline colonoscopy with complete removal of all detected neoplastic lesions.

Since 2013, new evidence has strengthened the idea that overutilization of endoscopic surveillance cannot compensate for an initially suboptimal colonoscopy. In a cohort of 11944 patients with a mean follow-up of nearly 8 years, a suboptimal examination has been shown to confer a higher risk of CRC incidence and mortality after polypectomy (incomplete colonoscopy, hazard ratio [HR] $1.8,95 \%$ confidence interval $[95 \% \mathrm{Cl}]$ 1.34-2.41; poor bowel preparation, HR 2.09, 95\%Cl 1.19$3.67)$, irrespective of the baseline risk and the performance of surveillance intervention [4].

Specific ESGE and World Endoscopy Organization (WEO) guidelines have already addressed the general principles of quality of colonoscopy, endoscopic resection, and bowel cleansing [24-26].

In the case of doubt about the completeness of endoscopic resection, such as positive or indefinite resection margins at pathology, an early repeat colonoscopy is recommended [24, 27] (see also Piecemeal resection). This is especially relevant when it is borne in mind that large polyp size, namely $\geq 20 \mathrm{~mm}$, has been strictly associated with increased long-term post-polypectomy CRC incidence/mortality risk (see below) [4,8]. Regarding the completeness of mucosal evaluation, an increased risk of metachronous advanced neoplasia has been reported in patients with $\geq 5$ adenomas with one $\geq 10 \mathrm{~mm}$ [28]. However, cohort studies based on the risk of CRC, rather than that of metachronous advanced neoplasia, have in general downgraded the role of both multiplicity and polyp size $<20 \mathrm{~mm}[7,8,29]$. Thus, it seems reasonable to recommend an early repeat colonoscopy only in those few cases where the number or complexity of multiple endoscopic resections have affected, according to endoscopist judgment, the quality of the baseline colonoscopy.

\section{Inadequate bowel preparation}

Strong recommendations for a 1-year repeat colonoscopy in the case of inadequate bowel preparation were issued by ESGE [24] recently and by other associations [30], strengthened by new evidence showing how a suboptimal baseline exam independently increases CRC incidence and mortality [4]. Of note, this recommendation is not followed in $90 \%$ of cases according to a colonoscopy registry of 9170 average risk patients with normal findings at screening colonoscopy [31].

The adenoma miss rate, but not the advanced adenoma miss rate, is independently associated with bowel preparation quality [32] and therefore standard guideline recommendations for surveillance intervals apply only to patients with adequate bowel preparation. There is no agreement on the definition of adequate bowel preparation [25]. ESGE defines adequate bowel preparation as: Boston Bowel Preparation Scale $\geq 6$, Ottawa Scale $\leq 7$, or Aronchick Scale excellent, good, or fair [26], while some authors have proposed that bowel preparation should be considered inadequate if the Boston Bowel Preparation Scale score is 0 or 1 in any colon segment [33]. One of these two definitions should be adopted by endoscopists as a necessary step to improve adherence to guideline recommendations.

\section{Polyp size evaluation}

\section{RECOMMENDATION}

2020 statement

When planning post-polypectomy surveillance, ESGE suggests to use a standardized measurement of polyp size evaluated at either endoscopy or pathology.

Weak recommendation, low quality evidence.

\section{3 statement}

No statement.

This is a new statement as compared with the 2013 Guideline. Surveillance interval recommendations depend strongly on polyp size, but measurement bias is present with evaluation both at endoscopy [34] and pathology [35]. It is known that at endoscopy size estimation is usually biased towards specific numbers (i.e., 5 or 10) while neglecting the others [34-36], and interobserver variability in visual polyp sizing can be present $[37,38]$, resulting in routine underestimation or overestimation of polyp size $[39,40]$. However, such bias can be reduced by using a reference standard, such as an open biopsy forceps or snare [41-43].

Endoscopic assessment of size is also useful in the case of piecemeal resection, as well as in cold-snaring, as the specimen sent for histology is much larger than the actual neoplastic component [27]. Size estimation at pathology also represents a feasible standard for en bloc resections, and it may be used for that purpose [35]. Technological improvements that permit real-time precise measurements during endoscopy should be expected in the near future $[41,43]$. 


\section{Appropriate scheduling of colonoscopy surveillance}

\section{RECOMMENDATION}

2020 statement

ESGE recommends provision of a written recommendation for the timing of post-polypectomy surveillance colonoscopy, considering all endoscopic, histological, and patient-related factors.

Strong recommendation, low quality evidence. This may be further reinforced by enhanced instructions. Weak recommendation, low quality evidence.

\section{3 statement}

ESGE recommends that the endoscopist is responsible for providing a written recommendation for the post-polypectomy surveillance schedule (strong recommendation, low quality evidence), and that this should be audited (weak recommendation, low quality evidence).

New evidence since 2013 shows the persistence of a high level of inappropriate post-polypectomy surveillance with a negative impact on colonoscopy efficiency. A systematic review published in 2019 and including 16 studies [44], showed correct adherence to current recommendations in only $48.8 \%(95 \% \mathrm{Cl}$ $37.3 \%-60.4 \%$ ) of cases. The surveillance interval was longer or shorter than currently recommended in $42.6 \%$ (95\% Cl $32.9 \%-$ $52.7 \%)$ and $7.9 \%(95 \% \mathrm{Cl} 0 \%-26.4 \%)$ of cases, respectively. These data are similar to data reported in 2013, when inappropriate surveillance accounted for $40 \%$ to $69 \%$ of the total.

The correct indication and timing for post-polypectomy surveillance is crucial as surveillance colonoscopies account for up to $40 \%$ of all colonoscopies performed [45]; consequently, the capacity of colonoscopy services is severely overburdened by the high demand associated with the implementation of CRC screening programs. It is estimated that one-third of all the surveillance-related endoscopic workload in an organized CRC screening program is wasted because of inappropriate surveillance examinations [46].

The appropriate surveillance interval depends on a combination of polyp characteristics (histology, number, and size), quality of colonoscopy, and clinical factors (patient age and co-morbidities). In one study, specialists in gastroenterology/ endoscopy appeared more likely to recommend appropriate surveillance intervals compared to other specialists [47]. Furthermore, a recent study has shown that endoscopists with an adenoma detection rate (ADR) $>20 \%$ are more likely to recommend correct surveillance [48].

For these reasons, the endoscopy unit should advise the patient on the appropriate surveillance interval with both written and oral instructions. Since histology reports become available only after the polypectomy, we recommend that the endoscopist update and/or finalize the colonoscopy report after receiving the histology report. The updated colonoscopy report should include a written recommendation on the appropriate surveillance interval, considering all endoscopic, histological, and patient-related factors. Any deviation from standard recommendations should be adequately explained in the report. Adherence to published surveillance guidelines should be monitored as part of a quality assurance program [26, 49, 50].

A 2015 cross-sectional study [51] has shown that higher perceived benefits and cancer worry are the major drivers for patients to seek surveillance colonoscopy after adenoma removal. Underuse of surveillance in groups at increased risk needs to be addressed as it may result in post-colonoscopy CRC. This is especially true for those with a clinically relevant risk of incomplete endoscopic resection. In this update, we suggest the use of enhanced instructions - which should be especially feasible in the setting of organized CRC screening programs - such as telephone calls and frequent email/postal reminders. These have been shown to improve adherence to surveillance colonoscopy, along with educational programs and facilitation of transportation [51-53].

\section{Patients not requiring surveillance after polypectomy}

\section{RECOMMENDATION}

2020 statement

ESGE recommends that patients with complete removal of $1-4<10 \mathrm{~mm}$ adenomas with low grade dysplasia, irrespective of villous components, or any serrated polyp $<10 \mathrm{~mm}$ without dysplasia, do not require endoscopic surveillance and should be returned to screening Strong recommendation, moderate quality evidence. If organized screening is not available, repetition of colonoscopy 10 years after the index examination is recommended.

Strong recommendation, moderate quality evidence.

\section{3 statement}

In the low risk group (patients with 1-2 tubular adenomas $<10 \mathrm{~mm}$ with low grade dysplasia), the ESGE recommends participation in existing national screening programmes 10 years after the index colonoscopy. If no screening programme is available, repetition of colonoscopy 10 years after the index colonoscopy is recommended (strong recommendation, moderate quality evidence).

\section{Conventional adenomas in patients not requiring surveillance}

Many studies from 2013 onwards [5, 7-9,54-62] have confirmed and strengthened the indication of "no surveillance/ return to screening" for patients with nonadvanced adenoma, showing how this group of patients have a long-term risk of CRC incidence and mortality lower than, or similar to, that of patients without any adenoma at baseline or that of the general population. For example, one study including 64422 patients 
with 14 years of mean follow-up [5] showed that patients with nonadvanced adenoma at baseline have a 10-year cumulative CRC incidence and mortality of $0.44 \%(95 \% \mathrm{Cl} 0.31 \%-0.62 \%)$ and $0.03 \%$ (95\% $\mathrm{Cl} 0.01 \%-0.11 \%)$, respectively, similarly to patients without adenoma at baseline. In patients with nonadvanced adenoma, the benefit of surveillance has been excluded by recent studies $[4,8,55]$ that showed how long-term CRC incidence without surveillance was similar to or even lower than that expected in the general population. Further details are available in Table $4 \mathrm{~s}$.

\section{Number of adenomas}

While confirming no surveillance for patients with $1-2<10 \mathrm{~mm}$ adenomas with low grade dysplasia, we decided to expand this to those with 3 or 4 polyps, based on new evidence. For example, three new large studies $[4,7,8]$ have addressed the role of multiplicity on post-polypectomy CRC risk. A retrospective series [7] of 15935 post-polypectomy patients showed that patients with $\geq 3$ nonadvanced adenomas had no increased risk of CRC incidence or mortality compared with those without adenomas (adjusted rate ratio [ARR] for incidence $1.3,95 \% \mathrm{Cl}$ 0.9 -1.9; ARR for mortality $1.2,95 \% \mathrm{Cl} 0.5-2.7$ ) after 13 years of follow-up. A second multicenter, retrospective study [4] of 11944 patients with 7.9 years of median follow-up also showed that the number of nonadvanced adenomas was not independently associated with a higher risk of CRC incidence or mortality, and that these patients remain at lower risk compared to the general population (standardized incidence ratio [SIR] 0.5, $95 \% \mathrm{Cl} 0.3-0.8]$. Finally, a recent multicenter, screening-based, retrospective series [8] of 236089 patients with 7.7 years of follow-up, confirmed that the number of adenomas or an adenoma size $<20 \mathrm{~mm}$ does not result in an increased risk of CRC incidence or mortality, showing that patients with any nonadvanced adenomas $<20 \mathrm{~mm}$ are at lower risk compared to the general population (SIR $0.35,95 \% \mathrm{Cl} 0.28-0.44$ ). In addition, when metachronous advanced neoplasia was used as a surrogate end point, 3-4 adenomas did not increase the risk of metachronous advanced neoplasia [27].

\section{Histological factors}

Patients whose polyps show villous histology have been moved into a nonsurveillance group. This is supported by recent evidence showing that villous histology does not independently confer a long-term increased risk of CRC incidence or mortality (HR 1.16, $95 \% \mathrm{Cl} 0.71-1.91)$ [4,8]. A meta-analysis and a pooled analysis had also previously reported that patients with polyps with villous histology $[63,64]$ had a risk of advanced neoplasia similar to that of controls.

It is also worth noting that the presence of villous histology in polyps $<10 \mathrm{~mm}$ and without high grade dysplasia is not common [9]. Furthermore, it is known that interpretation of villous histology has high interobserver variability among pathologists [65].

\section{Serrated polyps in patients not requiring surveillance}

Following publication of the 2013 ESGE Guideline, the risk of metachronous advanced neoplasia and CRC following resection of serrated polyps of size $<10 \mathrm{~mm}$ without dysplasia has been addressed by several studies [9,11,66-69]. Overall, no difference in advanced neoplasia and CRC incidence or mortality was seen after resection of serrated polyps $<10 \mathrm{~mm}$ without dysplasia or after resection of conventional adenomas which do not require surveillance. In particular, a recent retrospective study [9], including 122899 patients, demonstrated that patients with serrated polyps $<10 \mathrm{~mm}$ had a similar hazard ratio (HR) of metachronous CRC after 10 years of follow-up when compared to patients without adenomas (HR 1.25, $95 \% \mathrm{Cl}$ $0.76-2.08)$; the corresponding $\mathrm{HR}$ for patients with proximal serrated polyp was $1.11(95 \% \mathrm{Cl} 0.42-2.99)$ and for nonadvanced adenomas it was $1.21(95 \% \mathrm{Cl} 0.68-2.16)$. Further details are available in Table 5 s. On the other hand, no study assessed the possible benefit of surveillance in this group of patients, further excluding its efficacy at this stage.

\section{Patients requiring surveillance following polypectomy}

\section{RECOMMENDATION}

2020 statement

ESGE recommends surveillance colonoscopy after 3 years for patients with complete removal of at least 1 adenoma $\geq 10 \mathrm{~mm}$ or with high grade dysplasia, or $\geq 5$ adenomas, or any serrated polyp $\geq 10 \mathrm{~mm}$ or with dysplasia.

Strong recommendation, moderate quality evidence.

2013 statement

In the high risk group (patients with adenomas with villous histology or high grade dysplasia or $\geq 10 \mathrm{~mm}$ in size, or $\geq 3$ adenomas), ESGE recommends surveillance colonoscopy 3 years after the index colonoscopy (strong recommendation, moderate quality evidence). Patients with 10 or more adenomas should be referred for genetic counselling (strong recommendation, moderate quality evidence).

\section{Conventional adenomas in patients requiring surveillance}

As compared with the 2013 Guideline, we have confirmed the benefit of endoscopic surveillance in patients with an adenoma $\geq 10 \mathrm{~mm}$ or with high grade dysplasia (HGD), while for patients with multiplicity we limited it to those with $\geq 5$ adenomas. Many studies published after 2013, have strengthened this recommendation, as summarized in Table 4s.

Regarding patient baseline risk, a recent series [7], enrolling 15935 patients including 2882 advanced adenomas, with 13 years of median follow-up, reported an increased risk of CRC (ARR 3.0, 95\%Cl 2.1-4.3; $P<0.001$ ) and mortality (ARR 2.6, $95 \% \mathrm{Cl} 1.2-5.7 ; P<0.001)$ for those with advanced adenoma compared to those with no adenomas at baseline. A study including patients with adenomas from the Polish National Screening program [8] showed that only individuals with adenomas $\geq 20 \mathrm{~mm}$ and/or HGD carried an increased risk of CRC incidence and mortality. Patients with a baseline adenoma 
$\geq 20 \mathrm{~mm}$ had a higher risk of incident CRC (age-adjusted HR 9.25, $95 \% \mathrm{Cl} 6.39-13.39 ; P<0.001)$ and CRC death (age-adjusted HR 7.45, $95 \% \mathrm{Cl} 3.62-15.33$; $P<0.001)$ compared to individuals with no adenomas. HGD alone was also associated with a higher risk of incident CRC (age-adjusted HR 3.58, $95 \% \mathrm{Cl} 1.96-6.54$; $P<0.001)$ compared to individuals with no adenomas. As mentioned above, since only one retrospective study [8] specifically supported the shifting of the size cutoff from $10 \mathrm{~mm}$ to $20 \mathrm{~mm}$, we preferred not to advocate this shift systematically, underlining the importance of future research addressing baseline patient risk and efficacy of surveillance for polyps between 10 and $20 \mathrm{~mm}$. However, in the context of a health system with limited capacity, we suggest considering surveillance only for adenomas $\geq 20 \mathrm{~mm}$ in size or with HGD. Of course, patients with high risk conditions, such as those with serrated polyposis syndrome or hereditary syndromes should receive an individualized surveillance schedule.

Regarding the efficacy of the first surveillance colonoscopy, one study [4] showed how individuals with baseline high risk polyps significantly benefit from a first surveillance colonoscopy (HR of CRC compared to no surveillance $0.59,95 \% \mathrm{Cl} 0.36-$ $0.98)$, and this finding was confirmed by another recent study (HR of CRC compared to no surveillance 0.49 , 95\% Cl $0.29-$ 0.82 ) [70].

In line with the previous Guideline, we recommend performance of the first surveillance colonoscopy 3 years after baseline polypectomy. Atkin and colleagues compared the interval between index colonoscopy with polypectomy and the first surveillance colonoscopy, showing how the odds of detecting CRC at 2, 3 or 5 years were not statistically significant when compared to an interval of less than 18 months [4]. There is no current evidence addressing the surveillance interval and long-term CRC incidence and mortality. It should be noted that a large ongoing prospective randomized controlled trial (RCT) (European Polyp Surveillance [EPoS]; ClinicalTrials.gov NCT02319928) is addressing the possibility of extending the surveillance interval for high risk adenomas to 5 years [71].

\section{Serrated polyps in patients requiring surveillance}

Traditional serrated adenoma, serrated polyp $\geq 10 \mathrm{~mm}$ and serrated polyp with dysplasia yield similar metachronous advanced neoplasia or CRC risks compared to conventional adenomas, and thus require surveillance $[9-11,67,72,73]$. Therefore, ESGE recommends surveillance colonoscopy at 3 years for these categories of polyps. In detail, one population-based randomized study on 12955 patients screened with flexible sigmoidoscopy [10] showed that after resection of a serrated polyp $\geq 10 \mathrm{~mm}$ the adjusted HR for metachronous CRC was 4.2 (95\% Cl 1.3-13.3) compared to the general population. Another recent retrospective study [9] evaluating 122899 patients with 10 years of follow-up showed an increased HR for metachronous CRC $(3.35,95 \% \mathrm{Cl} 1.37-8.15)$ compared to negative colonoscopy. See Table 5s.

There is evidence that advanced adenoma with synchronous serrated polyp of any kind results in higher metachronous advanced neoplasia risk compared to advanced adenoma without synchronous serrated polyp $[68,73]$. However, such patients would already be classified as in need of surveillance, regardless of the presence of serrated polyps.

Any added value of combining adenomas with serrated polyp count to fulfill multiplicity criteria is therefore not supported by convincing evidence and requires further investigation.

Because of the high interobserver variation in serrated polyp classification [74-77], the risk of inaccurate histologic subclassification of serrated polyp is substantial and undesirable. In addition, a recent study demonstrated that the effect of taking into account serrated polyp subtype in surveillance guidelines is only marginal, and resulted in different surveillance intervals in only $2 \%$ of screened patients compared to a surveillance guideline not taking into account the serrated polyp subtype [78]. Therefore, to prevent undertreatment due to misclassification of serrated polyps, we recommend not to consider the serrated polyp subtype when choosing colonoscopy surveillance intervals.

\section{Patients at risk of hereditary syndromes}

RECOMMENDATION

2020 statement

ESGE recommends that patients with 10 or more adenomas should be referred for genetic counselling.

Strong recommendation, moderate quality evidence.

2013 statement

Incorporated unchanged into 2020 statement above.

Patients with adenomatous polyposis syndromes, such as familial adenomatous polyposis (FAP), MUTYH-associated polyposis (MAP), or rarer syndromes (including NHTL1-associated polyposis, and PPAP-associated polyposis), have an exceedingly high risk of developing colorectal cancer. The prevalence of pathogenic APC and biallelic MUTYH mutations, respectively, has been reported as $80 \%$ and $2 \%$ among individuals harboring $\geq 1000$ adenomas, as $56 \%$ and $7 \%$ among those with 100 to 999 adenomas, as $10 \%$ and $7 \%$ among those with 20 to 99 adenomas, and as $5 \%$ and $4 \%$ among those with 10 to 19 adenomas [79]. Furthermore, data from the Cleveland Clinic demonstrate that $4 \%$ of Lynch syndrome patients have a lifetime cumulative number of adenomas of $\geq 10$, prompting the consideration of Lynch syndrome in the differential diagnosis [80].

Thus, in line with the clinical practice guidelines of the European Society for Medical Oncology (ESMO), the National Comprehensive Cancer Network (NCCN), and ESGE [22,81-83], we recommend the referral of patients with 10 or more adenomas to specific genetic counselling and assessment for a cancerpredisposing syndrome. Furthermore, patients with $\geq 20$ lifetime cumulative adenomas should be tested for $A P C$ and MUTYH [82].

Tailored surveillance programs for patients with hereditary colorectal cancer syndromes are outside the scope of this present guideline and are addressed in the recent ESGE Guidelines on that topic [21, 22]. 


\section{Timing of second surveillance colonoscopy}

\section{RECOMMENDATION}

2020 statement

If no polyps requiring surveillance are detected at the first surveillance colonoscopy, ESGE suggests to perform a second surveillance colonoscopy after 5 years.

Weak recommendation, low quality evidence.

After that, if no polyps requiring surveillance are detected, patients can be returned to screening.

ESGE suggests that if polyps requiring surveillance are detected at first or subsequent surveillance examinations, surveillance colonoscopy may be performed at 3 years Weak recommendation, low quality evidence.

\section{3 statement}

In the high risk group, if no high risk adenomas are detected at the first surveillance examination, the ESGE suggests a 5year interval before a second surveillance colonoscopy (weak recommendation, low quality evidence). If high risk adenomas are detected at first or subsequent surveillance examinations, a 3-year repetition of surveillance colonoscopy is recommended (strong recommendation, low quality evidence). The ESGE found insufficient evidence to give recommendations in the case where no high risk adenomas are detected during 2 consecutive surveillance colonoscopies. However, intervals longer than 5 years appear reasonable (very low quality evidence).

Since 2013 new evidence $[4,7,9,70]$ has shown that patients with advanced adenoma at baseline remain at long-term higher risk of CRC incidence and mortality, irrespective of surveillance. In one study [70], the overall incidence of CRC in the high risk group after 10 years of follow-up was nearly double that of in the general population (SIR 1.91, $95 \% \mathrm{CI} 1.39-2.56$ ). Based on such increased CRC risk, we decided to suggest a second surveillance colonoscopy 5 years after the first. However, we also admit that evidence on the benefit of such a second surveillance colonoscopy on CRC risk is unclear. Two studies $[4,70]$ have shown no additional benefit of a second surveillance colonoscopy, although in the high risk group a trend toward a lower hazard ratio for CRC incidence was present (HR after first visit, 0.59 [ $95 \% \mathrm{Cl} 0.36-0.98]$, vs. HR after second visit 0.40 [0.21-0.77]) [4]. Thus, if resources are limited, second surveillance can be avoided, with patients directly returned to screening. On this evidence we also excluded a need for additional surveillance after the second surveillance colonoscopy, unless clinically relevant polyps are detected.

Previous studies with advanced adenoma as surrogate end points have shown that the findings at second surveillance colonoscopy are related to findings from the first surveillance colonoscopy rather than baseline features $[84,85]$. A recent abstract [86] reporting a retrospective cohort study on 17564 post-polypectomy patients in the UK screening program who underwent two surveillance colonoscopies showed that the second surveillance colonoscopy yielded similar rates of CRC irrespective of the findings at baseline or first colonoscopy.

There was no evidence for a statistically significant association between the risk of advanced adenoma at second surveillance colonoscopy and completeness of the colonoscopy at first surveillance; however, there was a significant association between the risk of CRC at second surveillance colonoscopy and the colonoscopy at first surveillance being reported as incomplete (OR 5.72, $95 \% \mathrm{Cl} 1.27$ - 25.87) [4, 14].

Two studies examined the interval between first and second surveillance $[4,14,87]$. The first study showed an increased risk of advanced neoplasia per year increase (OR $1.11,95 \% \mathrm{Cl}$ 1 -1.24). In multivariable models for advanced neoplasia, using an interval of less than 18 months as the referent standard, a 2year interval was not statistically significant, but intervals of 3 years (OR 2.02, $95 \% \mathrm{Cl} 1.19-3.42$ ), 4 years (OR 2.45, $[95 \% \mathrm{Cl}$ $1.20-5.00]$ ), and $>6.5$ years (OR 5.95, [95\%Cl 2.15-16.46]) were significant (an interval of 5 or 6 years was not significant). The second cohort did not show an association between risk for advanced adenoma and interval between first and second surveillance when the interval was $\geq 3$ years, compared with $<3$ years [87]. There was no evidence for the most appropriate interval between first and second surveillance as related to long-term CRC incidence or CRC mortality.

Details on mentioned studies are available in Table 6 s.

\section{Piecemeal resection}

\section{RECOMMENDATION}

2020 statement

ESGE recommends a 3-6-month early repeat colonoscopy following piecemeal endoscopic resection of polyps $\geq 20 \mathrm{~mm}$.

Strong recommendation, moderate quality evidence. A first surveillance colonoscopy 12 months after the repeat colonoscopy is recommended to detect late recurrence.

Strong recommendation, high quality evidence.

ESGE recommends evaluation of the post-piecemeal polypectomy site using advanced imaging techniques to detect neoplastic recurrence.

Strong recommendation, moderate quality evidence.

ESGE suggests that routine biopsy of the post-polypectomy scar can be abandoned provided that a standardized imaging protocol with virtual chromoendoscopy is used by a sufficiently trained endoscopist.

Weak recommendation, moderate quality evidence.

\section{3 statement}

In the case of piecemeal resection of adenomas larger than $10 \mathrm{~mm}$, endoscopic follow-up within 6 months is recommended before the patient is entered into a surveillance programme (strong recommendation, moderate quality evidence). 
Following our 2013 Guideline, several valuable studies have been published that evaluate adenoma recurrence rate following piecemeal endoscopic mucosal resection (EMR) in different subgroups. Details of these studies are available in Table 7s. Overall, a considerable rate $(12 \%-24 \%)$ of recurrence/residual adenomatous tissue after a successful endoscopic resection provides the rationale to recommend an early follow-up colonoscopy after piecemeal resection of nonpedunculated polyps, before the patient is entered into a surveillance program. As stated in the first recommendation above, after piecemeal resection and in the case of doubt about the completeness of endoscopic resection, an early repetition of colonoscopy is recommended [24,27]. A meta-analysis has shown that $75 \%$ of recurrences were found at 3 months, increasing to more than $90 \%$ at 6 months [88].

In contrast to the 2013 guideline, we have now pushed the threshold for recommending early follow-up colonoscopy to $20 \mathrm{~mm}$ lesions. Most of the data with follow-up after piecemeal resection include only lesions $20 \mathrm{~mm}$ or larger. The 2013 recommendation was based on a prospective trial evaluating completeness of polypectomy that showed inadequate resection in up to $17 \%$ of lesions $\geq 10 \mathrm{~mm}$ [89], especially if piecemeal polypectomy had been performed. However, there is no evidence on the possible consequences in terms of cancer incidence or mortality during follow-up of those patients. There are no data focused on recurrence/residual adenomatous tissue after piecemeal resection of $10-20 \mathrm{~mm}$ nonpedunculated polyps.

Nevertheless, cohort studies based on CRC risk, rather than metachronous advanced neoplasia risk, have in general downgraded the role of both multiplicity and polyp size $<20 \mathrm{~mm}$. Thus, apart from the larger than $20 \mathrm{~mm}$ adenomas, it seems reasonable to recommend an early repeat colonoscopy only in those few cases where the number or complexity of multiple endoscopic resections have affected, according to endoscopist judgment, the quality of the index colonoscopy.

\section{Intervals to recurrence, and predictors}

Despite the absence of recurrence/residual neoplasia during early follow-up colonoscopy, late recurrence at the resection site has been described in up to $5 \%-9 \%$ of cases. In a meta-analysis of 15 studies that differentiated between early and late recurrences, $12 \%$ of neoplastic recurrences occurred late [88]. A large Australian prospective multicenter study [90] based on wide-field EMR for laterally spreading tumors (LSTs) larger than $20 \mathrm{~mm}$ (mean lesion size $36.4 \mathrm{~mm}$, SD $17 \mathrm{~mm}$ ) that included 799 successful EMRs ( $82 \%$ piecemeal, $18 \%$ en bloc) with follow-up, has shown a $16 \%(95 \% \mathrm{Cl} 13.6 \%-18.7 \%)$ recurrence/ residual adenoma rate at 4-6 months. Of note, $17 / 426(4 \%$, $95 \% \mathrm{Cl} 2.4 \%-6.2 \%$ ) with no adenoma at first follow-up colonoscopy presented with late recurrence after 16 months. Another analysis from the same cohort of patients, included 1018 adenomas and 190 sessile serrated lesions (SSLs) $\geq 20 \mathrm{~mm}$ removed by EMR and with follow-up [91]. It showed cumulative recurrence rates for adenomas after $6,12,18$, and 24 months of $16.1 \%, 20.4 \%, 23.4 \%$, and $28.4 \%$, respectively; the corresponding rates for SSLs were significantly lower, being $6.3 \%$ at 6 months and $7.0 \%$ from 12 months onwards $(P<0.001)$. Recurrences were identified at the first surveillance colonoscopy in $90 \%$ of cases [91].

A post hoc analysis of the above cohort, including 1178 patients [92] has proven the possibility of predicting recurrence after piecemeal EMR shortly after index examination. In this study the authors proposed and validated the so-called Sydney EMR Recurrence Tool (SERT), consisting of the following factors: size of $40 \mathrm{~mm}$ or more (2 points), intraprocedural bleeding (1 point), and HGD (1 point). The endoscopically detected recurrence rate was $19.4 \%$ overall. However, for SERT 0 , early recurrence was only $8.7 \%$ at $4-6$ months and such recurrent neoplastic lesions were very small and easy to remove; in contrast, for SERT scores 2- 4 the neoplastic recurrence rate was $25.9 \%$.

A study from Japan [93] has shown that a higher number of pieces during piecemeal resection was associated with a shorter interval to recurrence ( $9-10$ months when $2-3$ pieces were retrieved vs. $3.8-5$ months in the case of more than 4 pieces retrieved).

Therefore, we recommend, especially in those cases at high risk of recurrence (larger lesions, HGD, multiple pieces), a first surveillance colonoscopy 12 months after the early follow-up, even in the absence of recurrence/residual adenomatous tissue.

\section{Reducing recurrence risk after piecemeal polypectomy}

Two recent studies $[94,95]$ have evaluated ways of decreasing the risk of early recurrence following piecemeal polypectomy. First, an RCT tested whether thermal ablation of resection margins of LSTs larger than $20 \mathrm{~mm}$ might decrease the risk of early recurrence [94]. The authors included 390 EMRs, of which a majority ( $83 \%$ ) were piecemeal, and detected that recurrence in the ablation arm was only $5.2 \%$ vs. $21 \%$ in the control arm. For the piecemeal subgroup the values were similar $(5.4 \%$ vs. $24.2 \%$ ), as well as for the size $\geq 40 \mathrm{~mm}$ subgroup (6.1\% vs. $36.4 \%)$. The overall cumulative recurrence rate at surveillance endoscopy at 18 months was also significantly lower (7.4\% vs. $27.1 \%)$.

The second study [95], although retrospective in design, reported that underwater piecemeal polypectomy without injection resulted in a significantly lower recurrence rate at 6 months (7.3\% vs. $28.3 \%)$.

While we need further corroboration of these promising results, we recommend the use of any proven technique, e.g. thermal ablation of EMR margins, to prevent recurrence after piecemeal resection.

\section{Roles of advanced endoscopic imaging and biopsy}

It has been shown that inspection with white light alone may miss residual neoplastic tissue on an EMR scar and therefore, performance of targeted and random biopsies used to be recommended $[96,97]$. However, recent studies have shown that evaluation using advanced endoscopic imaging at the first surveillance examination of the post-polypectomy scar following piecemeal EMR is highly accurate $[98,99]$; this may allow decisions concerning removal of recurrences without the need for biopsies. Accordingly, the updated 2019 ESGE Guideline, on 
advanced imaging for detection and differentiation of colorectal neoplasia [100] recommends the use of virtual or dye-based chromoendoscopy in addition to white-light endoscopy for the detection of residual neoplasia at a piecemeal polypectomy scar site, and suggests that routine biopsy of post-polypectomy scars can be abandoned provided that a standardized imaging protocol with virtual chromoendoscopy is used by a sufficiently trained endoscopist.

\section{Family history}

\section{RECOMMENDATION}

2020 statement

ESGE suggests against shortened surveillance intervals after polypectomy in patients with a family history of CRC Weak recommendation, low quality evidence.

\section{3 statement}

The ESGE found insufficient evidence to provide recommendations on post-polypectomy surveillance based on other potential risk factors, such as age, or family history of CRC (very low quality evidence).

In line with the 2013 Guideline, and based on updated data, we still do not support different surveillance recommendations for individuals with a family history of CRC. Since 2013, several studies have addressed the relationship between recurrent advanced neoplastic polyps and family history; the majority of these studies are of low quality, but all found no increased risk for advanced neoplasia at surveillance colonoscopies in patients with a CRC family history [67, $101-108]$. Moreover, a pooled analysis of prospective studies [109], including 8 studies (of which 6 were RCTs) on 7697 patients with adenomas, found no increased risk for advanced colorectal neoplasia in patients with family history (OR 1.15, 95\% Cl 0.96-1.37). Details of the aforementioned studies are available in Table 8s.

More well-designed studies are needed, randomized and stratified by family risk and baseline adenoma characteristics.

\section{Stopping post-polypectomy surveillance}

\section{RECOMMENDATION}

2020 statement

ESGE suggests stopping post-polypectomy endoscopic surveillance at the age of 80 years, or earlier if life expectancy is thought to be limited by co-morbidities. Weak recommendation, low quality evidence.

\section{3 statement}

[I] t seems reasonable to stop endoscopic surveillance at 80 years, or earlier depending on life expectancy (in the case of co-morbidities).

CRC screening is generally recommended until 74 years of age because of its limited efficacy after this age due to competing causes of death [110]. Taking into consideration the 3-year interval for first surveillance, a patient would still undergo the first surveillance colonoscopy before the limit of 80 years. Bearing in mind the uncertainty regarding the efficacy of additional surveillance procedures, as well as the actual benefit of CRC prevention in general on overall life expectancy, this cutoff for halting surveillance appears appropriate. In addition, such a recommendation would also prevent possible adverse events related to colonoscopy that have been shown to sharply increase in older patients or in patients with co-morbidities [13].

\section{Fecal immunochemical testing (FIT)}

\section{RECOMMENDATION}

2020 statement

ESGE did not find enough evidence on the use of fecal immunochemical testing (FIT) for post-polypectomy surveillance. In the case of an unplanned positive FIT, ESGE suggests to consider repeat colonoscopy based on clinical judgment.

Weak recommendation, low quality evidence.

Overall, we reaffirm our previous 2013 recommendation. A recent study [111] detailing 5946 post-polypectomy “intermediate-risk" patients ( $3-4$ adenomas $<10 \mathrm{~mm}$, or $1-2$ adenomas with one $\geq 10 \mathrm{~mm}$ ) aimed to assess the efficacy of three annual rounds of FIT versus colonoscopy surveillance at 3 years for detection of CRC and advanced adenoma. This study demonstrated that in these intermediate risk patients, annual FIT with low threshold levels for fecal hemoglobin $(\mathrm{Hb})(10 \mu \mathrm{g} / \mathrm{g})$ had a high sensitivity for the detection of CRC (three cumulative tests: sensitivity $91.7 \%[95 \% \mathrm{Cl} 73.0-99.0]$, specificity $69.8 \%$ [95\% Cl 68.5-71.1]). Higher cutoffs for fecal Hb showed high miss rates for CRC and advanced adenomas. Furthermore, the study showed how three annual FITs are cost-effective com- 
pared to colonoscopy surveillance at 3 years. Further clinical implementation studies should confirm these results and define the most efficient fecal $\mathrm{Hb}$ thresholds before routine recommendations for clinical practice can be issued.

In patients with an unplanned, positive FIT test, we reaffirm our 2013 statement suggesting repeat colonoscopy based on clinical judgment. A recent study [112] that compared patients with positive versus negative FIT after a recent colonoscopy ( $<3$ years), found higher rates of CRC and advanced adenoma among patients with positive FIT (CRC rate: FIT-positive $2.1 \%$ vs. FIT-negative $0.7 \%$ ) (Table 9s). However, in this study, the characteristics of the prior recent colonoscopy were unknown, and these results must be confirmed by further research.

\section{Symptomatic patients}

\section{RECOMMENDATION}

2020 statement

ESGE suggests that individuals with symptoms in the surveillance interval should be managed as clinically indicated.

Weak recommendation, low quality evidence.

\section{3 statement}

The ESGE suggests that individuals with symptoms in the surveillance interval should be managed as clinically indicated (weak recommendation, low quality evidence).

We found insufficient evidence to modify the 2013 Guideline statement.

Irrespective of post-polypectomy surveillance, two models have been designed to help identify symptomatic patients for whom prioritization of colonoscopy is warranted $[113,114]$. The first model found that age was the dominant risk factor in detecting patients with CRC (ORs, vs. the reference $<50$ years, for ages $50-59$ and $\geq 70$, were 6.84 [ $95 \% \mathrm{Cl} 3.33-14.06]$ and 23.54 [ $95 \% \mathrm{Cl} 11.43-48.45]$, respectively) [113]. The four symptoms associated with CRC were bleeding, mucus, anemia, and fatigue. The most recent model included FIT, which has increasingly been recommended for prioritizing symptomatic patients for colonoscopy [115]. This model was able to predict advanced colorectal neoplasia with an area under the curve (AUC) of 0.87 in a prospective study (1495 patients) [114].

\section{Disclaimer}

ESGE Guidelines represent a consensus of best practice based on the available evidence at the time of preparation. They may not apply to all situations and should be interpreted in the setting of specific clinical situations and resource availability. They are intended to be an educational tool to provide information that may support endoscopists in providing care to patients. They are not rules and should not be utilized to establish a legal standard of care.

\section{Acknowledgment}

The authors are grateful to Professor Helmut Messman of the Klinikum Augsburg and Professor Ian Gralnek of the TechnionIsrael Institute of Technology for their review of the manuscript.

\section{Competing interests}

M. Bretthauer's department has received support and cooperation from the EndoBRAIN study from Olympus Europa SE (from 2019 ongoing). E. Dekker has received consultancy honoraria from Fujifilm, Olympus, Tillots, GI Supply, and CPP-FAP, and speakers' fees from Olympus, Roche and GI Supply; she has endoscopic equipment on loan and receives a research grant from Fujifilm. L.M. Helsingen's department has received support and cooperation from the EndoBRAIN study from Olympus Europa SE (from 2019 ongoing). J.E. van Hooft has received lecture fees from Medtronics (from 2014 to 2015 and 2019) and Cook Medical (2019), and consultancy fees from Boston Scientific (2014 - 2017); her department has received research grants from Cook Medical (2014 - 2019) and Abbott (2014 - 2017). M. Pellisé has received consultancy and speaker's fees from Norgine Iberia (2015-2019), a consultancy fee from GI Supply (2019), speaker's fees from Casen Recordati (2016 - 2019), Olympus (2018), and Jansen (2018), and research funding from Fujifilm Spain (2019), Fujifilm Europe (2020), and Casen Recordati (2020); her department has received loan material from Fujifilm Spain (from 2017 ongoing), a research grant from Olympus Europe (2005 - 2019), and loan material and a research grant from Fujifilm Europe (2020 - 2021); she is a Board member of ESGE and SEED; and receives a fee from Thieme as an Endoscopy Co-Editor. J. Regula has received sponsorship and lecture fees from Ipsen Pharma and Alfasigma (2017-2020). M. Rutter is a member of the British Society of Gastroenterology. G. Antonelli, A. Bleijenberg, S. Chaussade, M. Dinis-Ribeiro, J.-M. Dumonceau, M. Ferlitsch, A. Gimeno-Garcia, C. Hassan, R. Jover, M. Kalager, C. Pox, E. Quintero, and L. Ricciardello, and C. Senore have no competing interests.

\section{References}

[1] Hassan C, Quintero E, Dumonceau J-M et al. Post-polypectomy colonoscopy surveillance: European Society of Gastrointestinal Endoscopy (ESGE) Guideline. Endoscopy 2013; 45: 842-851

[2] Dumonceau J-M, Hassan C, Riphaus A et al. European Society of Gastrointestinal Endoscopy (ESGE) Guideline Development Policy. Endoscopy 2012; 44: 626-629

[3] Guyatt GH, Oxman AD, Vist GE et al. GRADE: An emerging consensus on rating quality of evidence and strength of recommendations. BMJ 2008; 336: 924-926

[4] Atkin W, Wooldrage K, Brenner A et al. Adenoma surveillance and colorectal cancer incidence: a retrospective, multicentre, cohort study. Lancet Oncol 2017; 18: 823-834

[5] Lee JK, Jensen CD, Levin TR et al. Long-term risk of colorectal cancer and related death after adenoma removal in a large, communitybased population. Gastroenterology 2020; 158: 884-894

[6] Helsingen LM, Vandvik PO, Jodal HC et al. Colorectal cancer screening with faecal immunochemical testing, sigmoidoscopy or colonoscopy: a clinical practice guideline. BMJ 2019; 367: 15515

[7] Click B, Pinsky PF, Hickey T et al. Association of colonoscopy adenoma findings with long-term colorectal cancer incidence. JAMA 2018 319: 2021-2031 
[8] Wieszczy P, Kaminski MF, Franczyk R et al. Colorectal cancer incidence and mortality after removal of adenomas during screening colonoscopies. Gastroenterology 2020; 158: 875-883

[9] He X, Hang D, Wu K et al. Long-term risk of colorectal cancer after removal of conventional adenomas and serrated polyps. Gastroenterology 2020; 158: 852-861

[10] Holme $\varnothing$, Bretthauer M, Eide T] et al. Long-term risk of colorectal cancer in individuals with serrated polyps. Gut 2015; 64: 929-936

[11] Erichsen R, Baron JA, Hamilton-Dutoit SJ et al. Increased risk of colorectal cancer development among patients with serrated polyps. Gastroenterology 2016; 150: 895-902.e5

[12] Reumkens A, Rondagh EJA, Bakker CM et al. Post-colonoscopy complications: a systematic review, time trends, and meta-analysis of population-based studies. Am J Gastroenterol 2016; 111: 10921101

[13] Tran AH, Man NgorEW, Wu BU. Surveillance colonoscopy in elderly patients: a retrospective cohort study. JAMA Intern Med 2014; 174: 1675-1682

[14] Atkin W, Brenner A, Martin J et al. The clinical effectiveness of different surveillance strategies to prevent colorectal cancer in people with intermediate-grade colorectal adenomas: a retrospective cohort analysis, and psychological and economic evaluations. Health Technol Assess 2017; 21: 1-536

[15] Rex DK, Repici A, Gross SA et al. High-definition colonoscopy versus Endocuff versus EndoRings versus full-spectrum endoscopy for adenoma detection at colonoscopy: a multicenter randomized trial. Gastrointest Endosc 2018; 88: 335-344.e2

[16] Greuter MJE, de Klerk CM, Meijer GA et al. Screening for colorectal cancer with fecal immunochemical testing with and without postpolypectomy surveillance colonoscopy: a cost-effectiveness analysis. Ann Intern Med 2017; 167: 544-554

[17] Joseph GN, Heidarnejad F, Sherer EA. Evaluating the cost-effective use of follow-up colonoscopy based on screening findings and age. Comput Math Methods Med 2019; 2019: 2476565. doi:10.1155/ 2019/2476565

[18] McFerran E, O'Mahony JF, Fallis R et al. Evaluation of the effectiveness and cost-effectiveness of personalized surveillance after colorectal adenomatous polypectomy. Epidemiol Rev 2017; 39: 148160

[19] Richardson WS, Wilson MC, Nishikawa J et al. The well-built clinical question: a key to evidence-based decisions. ACP J Club 1995; 123 A12-A13

[20] Hassan C, Wysocki PT, Fuccio L et al. Endoscopic surveillance after surgical or endoscopic resection for colorectal cancer: European Society of Gastrointestinal Endoscopy (ESGE) and European Society of Digestive Oncology (ESDO) Guideline. Endoscopy 2019; 51: 266277

[21] van Leerdam ME, Roos VH, van Hooft JE et al. Endoscopic management of Lynch syndrome and of familial risk of colorectal cancer: European Society of Gastrointestinal Endoscopy (ESGE) Guideline. Endoscopy 2019; 51: 1082-1093

[22] van Leerdam ME, Roos VH, van Hooft JE et al. Endoscopic management of polyposis syndromes: European Society of Gastrointestinal Endoscopy (ESGE) Guideline. Endoscopy 2019; 51: 877-895

[23] Grade Working Group. Grading quality of evidence and strength of recommendations. BMJ 2004; 328: 1490. doi:https://www.bmj. com/content/328/7454/1490

[24] Hassan C, East J, Radaelli F et al. Bowel preparation for colonoscopy: European Society of Gastrointestinal Endoscopy (ESGE) Guideline Update 2019. Endoscopy 2019; 51: 775-794

[25] Jover R, Dekker E, Schoen RE. WEO Expert Working Group of Surveillance after colonic neoplasm. et al. Colonoscopy quality requisites for selecting surveillance intervals: A World Endoscopy Organization Delphi Recommendation. Dig Endosc 2018; 30: 750-759
[26] Kaminski M, Thomas-Gibson S, Bugajski M et al. Performance measures for lower gastrointestinal endoscopy: a European Society of Gastrointestinal Endoscopy (ESGE) Quality Improvement Initiative. Endoscopy 2017; 49: 378-397

[27] Ferlitsch M, Moss A, Hassan C et al. Colorectal polypectomy and endoscopic mucosal resection (EMR): European Society of Gastrointestinal Endoscopy (ESGE) Clinical Guideline. Endoscopy 2017; 49: 270-297

[28] Vemulapalli KC, Rex DK. Risk of advanced lesions at first follow-up colonoscopy in high-risk groups as defined by the United Kingdom post-polypectomy surveillance guideline: data from a single U.S. center. Gastrointest Endosc 2014; 80: 299-306

[29] Vleugels JLA, Hassan C, Senore C et al. Diminutive polyps with advanced histologic features do not increase risk for metachronous advanced colon neoplasia. Gastroenterology 2019; 156: 623-634. e3

[30] Lieberman DA, Rex DK, Winawer S] et al. Guidelines for colonoscopy surveillance after screening and polypectomy: A consensus update by the US Multi-Society Task Force on Colorectal Cancer. Gastroenterology 2012; 143: 844-857

[31] Butterly LF, Nadel MR, Anderson JC et al. Impact of colonoscopy bowel preparation quality on follow-up interval recommendations for average-risk patients with normal screening colonoscopies: data from the New Hampshire Colonoscopy Registry. J Clin Gastroenterol 2020; 54: 356-364

[32] Zhao S, Wang S, Pan P et al. Magnitude, risk factors, and factors associated with adenoma miss rate of tandem colonoscopy: a systematic review and meta-analysis. Gastroenterology 2019; 156: 1661-1674.e11

[33] Clark BT, Protiva P, Nagar A et al. Quantification of adequate bowel preparation for screening or surveillance colonoscopy in men. Gastroenterology 2016; 150: 396-405

[34] Sakata S, Klein K, Stevenson ARL et al. Measurement bias of polyp size at colonoscopy. Dis Colon Rectum 2017; 60: 987-991

[35] Plumb AA, Nickerson C, Wooldrage K et al. Terminal digit preference biases polyp size measurements at endoscopy, computed tomographic colonography, and histopathology. Endoscopy 2016; 48: 899-908

[36] Utsumi T, Horimatsu T, Seno H. Measurement bias of colorectal polyp size: Analysis of the Japan Endoscopy Database. Dig Endosc 2019; 31: 589

[37] Buijs MM, Steele RJC, Buch N et al. Reproducibility and accuracy of visual estimation of polyp size in large colorectal polyps. Acta Oncol 2019; 58: S37-S41

[38] Elwir S, Shaukat A, Shaw M et al. Variability in, and factors associated with, sizing of polyps by endoscopists at a large community practice. Endosc Int Open 2017; 5: E742-E745

[39] Eichenseer PJ, Dhanekula R, Jakate S et al. Endoscopic mis-sizing of polyps changes colorectal cancer surveillance recommendations. Dis Colon Rectum 2013; 56: 315-321

[40] Anderson BW, Smyrk TC, Anderson KS et al. Endoscopic overestimation of colorectal polyp size. Gastrointest Endosc 2016; 83: 201 208

[41] Sakata S, Mclvor F, Klein K et al. Measurement of polyp size at colonoscopy: a proof-of-concept simulation study to address technology bias. Gut 2018; 67: 206-208

[42] Hassan C, Repici A, Rex D. Addressing bias in polyp size measurement. Endoscopy 2016; 48: 881-883

[43] Sakata S, Grove PM, Stevenson ARL et al. The impact of three-dimensional imaging on polyp detection during colonoscopy: a proof of concept study. Gut 2016; 65: 730-731 
[44] Djinbachian R, Dubé A-J, Durand M et al. Adherence to post-polypectomy surveillance guidelines: a systematic review and meta-analysis. Endoscopy 2019; 51: 673-683

[45] van Heijningen E-MB, Lansdorp-Vogelaar I, Steyerberg EW et al. Adherence to surveillance guidelines after removal of colorectal adenomas: a large, community-based study. Gut 2015; 64: 1584-1592

[46] Zorzi M, Senore C, Turrin A et al. Appropriateness of endoscopic surveillance recommendations in organised colorectal cancer screening programmes based on the faecal immunochemical test. Gut 2016; 65: 1822-1828

[47] Hong S, Suh M, Choi KS et al. Guideline adherence to colonoscopic surveillance intervals after polypectomy in Korea: results from a nationwide survey. Gut Liver 2018; 12: 426-432

[48] Gessl I, Waldmann E, Britto-Arias M et al. Surveillance colonoscopy in Austria: Are we following the guidelines? Endoscopy 2018; 50: 119-127

[49] Lieberman D, Nadel M, Smith RA et al. Standardized colonoscopy reporting and data system: report of the Quality Assurance Task Group of the National Colorectal Cancer Roundtable. Gastrointest Endosc 2007; 65: 757-766

[50] Atkin WS, Valori R, Kuipers EJ et al. International Agency for Research on Cancer. European guidelines for quality assurance in colorectal cancer screening and diagnosis. First edition - Colonoscopic surveillance following adenoma removal. Endoscopy 2012; 44 (Suppl. 03): SE151-SE163

[51] Murphy CC, Lewis CL, Golin CE et al. Underuse of surveillance colonoscopy in patients at increased risk of colorectal cancer. Am J Gastroenterol 2015; 110: 633-641

[52] Hassan C, Kaminski MF, Repici A. How to ensure patient adherence to colorectal cancer screening and surveillance in your practice. Gastroenterology 2018; 155: 252-257

[53] Gauci C, Lendzion R, Phan-Thien K-C et al. Patient compliance with surveillance colonoscopy: patient factors and the use of a graded recall system: Compliance with surveillance colonoscopy. ANZ J Surg 2018; 88: 311-315

[54] Vleugels JLA, Hazewinkel Y, Fockens P et al. Natural history of diminutive and small colorectal polyps: a systematic literature review. Gastrointest Endosc 2017; 85: 1169-1176.e1

[55] Cottet V, Jooste V, Fournel I et al. Long-term risk of colorectal cancer after adenoma removal: a population-based cohort study. Gut 2012; 61: $1180-1186$

[56] Ponugoti PL, Cummings OW, Rex DK. Risk of cancer in small and diminutive colorectal polyps. Dig Liver Dis 2017; 49: 34-37

[57] Gupta N, Bansal A, Rao D et al. Prevalence of advanced histological features in diminutive and small colon polyps. Gastrointest Endosc 2012; 75: 1022-1030

[58] Turner KO, Genta RM, Sonnenberg A. Lesions of all types exist in colon polyps of all sizes. Am J Gastroenterol 2018; 113: 303-306

[59] Brenner H, Chang-Claude J, Rickert A et al. Risk of colorectal cancer after detection and removal of adenomas at colonoscopy: population-based case-control study. J Clin Oncol 2012; 30: 2969-2976

[60] Løberg M, Kalager M, Holme Ø et al. Long-term colorectal-cancer mortality after adenoma removal. N Engl J Med 2014; 371: 799-807

[61] Ren J, Kirkness CS, Kim M et al. Long-term risk of colorectal cancer by gender after positive colonoscopy: population-based cohort study. Curr Med Res Opin 2016; 32: 1367-1374

[62] Dubé C, Yakubu M, McCurdy BR et al. Risk of advanced adenoma, colorectal cancer, and colorectal cancer mortality in people with low-risk adenomas at baseline colonoscopy: a systematic review and meta-analysis. Am J Gastroenterol 2017; 112: 1790-1801
[63] Saini SD, Kim HM, Schoenfeld P. Incidence of advanced adenomas at surveillance colonoscopy in patients with a personal history of colon adenomas: a meta-analysis and systematic review. Gastrointest Endosc 2006; 64: 614-626

[64] de Jonge $V$, Sint Nicolaas J, van Leerdam M et al. Systematic literature review and pooled analyses of risk factors for finding adenomas at surveillance colonoscopy. Endoscopy 2011; 43: 560-574

[65] Mahajan D, Downs-Kelly E, Liu X et al. Reproducibility of the villous component and high-grade dysplasia in colorectal adenomas $<1 \mathrm{~cm}$ : implications for endoscopic surveillance. Am J Surg Pathol 2013; 37 : 427-433

[66] Macaron C, Vu HT, Lopez R et al. Risk of metachronous polyps in individuals with serrated polyps. Dis Colon Rectum 2015; 58: 762-768

[67] Lee JY, Park HW, Kim M-J et al. Prediction of the risk of a metachronous advanced colorectal neoplasm using a novel scoring system. Dig Dis Sci 2016; 61: 3016-3025

[68] Pereyra L, Zamora R, Gómez EJ et al. Risk of metachronous advanced neoplastic lesions in patients with sporadic sessile serrated adenomas undergoing colonoscopic surveillance. Am J Gastroenterol 2016; 111: 871-878

[69] Symonds E, Anwar S, Young G et al. Sessile serrated polyps with synchronous conventional adenomas increase risk of future advanced neoplasia. Dig Dis Sci 2019; 64: 1680-1685

[70] Cross AJ, Robbins EC, Pack K et al. Long-term colorectal cancer incidence after adenoma removal and the effects of surveillance on incidence: a multicentre, retrospective, cohort study. Gut 2020: doi:10.1136/gutjnl-2019-320036

[71] Jover R, Bretthauer M, Dekker E et al. Rationale and design of the European Polyp Surveillance (EPoS) trials. Endoscopy 2016; 48: $571-$ 578

[72] Yoon JY, Kim HT, Hong SP et al. High-risk metachronous polyps are more frequent in patients with traditional serrated adenomas than in patients with conventional adenomas: a multicenter prospective study. Gastrointest Endosc 2015; 82: 1087-1093.e3

[73] Anderson JC, Butterly LF, Robinson CM et al. Risk of metachronous high-risk adenomas and large serrated polyps in individuals with serrated polyps on index colonoscopy: data from the New Hampshire Colonoscopy Registry. Gastroenterology 2018; 154: 117-127. e2

[74] Schachschal G, Sehner S, Choschzick M et al. Impact of reassessment of colonic hyperplastic polyps by expert $\mathrm{GI}$ pathologists. Int J Colorectal Dis 2016; 31: 675-683

[75] IJspeert JEG, Madani A, Overbeek LIH et al. Implementation of an elearning module improves consistency in the histopathological diagnosis of sessile serrated lesions within a nationwide population screening programme. Histopathology 2017; 70: 929-937

[76] Khalid O, Radaideh S, Cummings OW et al. Reinterpretation of histology of proximal colon polyps called hyperplastic in 2001. World J Gastroenterol 2009; 15: 3767-3770

[77] Abdeljawad K, Vemulapalli KC, Kahi C] et al. Sessile serrated polyp prevalence determined by a colonoscopist with a high lesion detection rate and an experienced pathologist. Gastrointest Endosc 2015; 81: 517-524

[78] Bleijenberg A, Klotz D, Løberg M et al. Implications of different guidelines for surveillance after serrated polyp resection in United States of America and Europe. Endoscopy 2019; 51: 750-758

[79] Grover S, Kastrinos F, Steyerberg EW et al. Prevalence and phenotypes of APC and MUTYH mutations in patients with multiple colorectal adenomas. JAMA 2012; 308: 485-492

[80] Kalady MF, Kravochuck SE, Heald B et al. Defining the adenoma burden in lynch syndrome. Dis Colon Rectum 2015; 58: 388-392 
[81] Stjepanovic N, Moreira L, Carneiro F et al. ESMO Guidelines Committee. Hereditary gastrointestinal cancers: ESMO Clinical Practice Guidelines for diagnosis, treatment and follow-up. Ann Oncol 2019; 30: $1558-1571$

[82] Gupta S, Provenzale D, Regenbogen SE et al. NCCN Guidelines insights: genetic/familial high-risk assessment: colorectal, version 3.2017. J Natl Compr Canc Netw 2017; 15: 1465-1475

[83] Benson AB, Venook AP, Al-Hawary MM et al. NCCN Guidelines insights: colon cancer, version 2. J Natl Compr Canc Netw 2018; 16: 359-369

[84] Pinsky PF, Schoen RE, Weissfeld JL et al. The yield of surveillance colonoscopy by adenoma history and time to examination. Clin Gastroenterol Hepatol 2009; 7: 86-92

[85] Morelli MS, Glowinski EA, Juluri R et al. Yield of the second surveillance colonoscopy based on the results of the index and first surveillance colonoscopies. Endoscopy 2013; 45: 821-826

[86] Bonnington S, Sharp L, Rutter M. Post-polypectomy surveillance in the English Bowel Cancer Screening Programme: multivariate logistic regression of factors influencing advanced adenoma detection at first surveillance. Endoscopy 2019; 51: ePP79. doi:10.1055/s-00391681622

[87] Mehta N, Miller J, Feldman M et al. Findings on serial surveillance colonoscopy in patients with low-risk polyps on initial colonoscopy. J Clin Gastroenterol 2010; 44: e46-e50

[88] Belderbos TDG, Leenders M, Moons LMG et al. Local recurrence after endoscopic mucosal resection of nonpedunculated colorectal lesions: systematic review and meta-analysis. Endoscopy 2014; 46: 388-402

[89] Pohl H, Srivastava A, Bensen SP et al. Incomplete polyp resection during colonoscopy-results of the complete adenoma resection (CARE) study. Gastroenterology 2013; 144: 74-80.e1

[90] Moss A, Williams S], Hourigan LF et al. Long-term adenoma recurrence following wide-field endoscopic mucosal resection (WF-EMR) for advanced colonic mucosal neoplasia is infrequent: results and risk factors in 1000 cases from the Australian Colonic EMR (ACE) study. Gut 2015; 64: 57-65

[91] Pellise M, Burgess NG, Tutticci N et al. Endoscopic mucosal resection for large serrated lesions in comparison with adenomas: a prospective multicentre study of 2000 lesions. Gut 2017; 66: 644-653

[92] Tate DJ, Desomer L, Klein A et al. Adenoma recurrence after piecemeal colonic EMR is predictable: the Sydney EMR recurrence tool. Gastrointest Endosc 2017; 85: 647-656.e6

[93] Komeda Y, Watanabe T, Sakurai T et al. Risk factors for local recurrence and appropriate surveillance interval after endoscopic resection. World J Gastroenterol 2019; 25: 1502-1512

[94] Klein A, Tate DJ, Jayasekeran V et al. Thermal ablation of mucosal defect margins reduces adenoma recurrence after colonic endoscopic mucosal resection. Gastroenterology 2019; 156: 604-613.e3

[95] Schenck RJ, Jahann DA, Patrie JT et al. Underwater endoscopic mucosal resection is associated with fewer recurrences and earlier curative resections compared to conventional endoscopic mucosal resection for large colorectal polyps. Surg Endosc 2017; 31: 41744183

[96] Shahid MW, Buchner AM, Heckman MG et al. Diagnostic accuracy of probe-based confocal laser endomicroscopy and narrow band imaging for small colorectal polyps: a feasibility study. Am J Gastroenterol 2012; 107: 231-239

[97] Khashab M, Eid E, Rusche M et al. Incidence and predictors of "late" recurrences after endoscopic piecemeal resection of large sessile adenomas. Gastrointest Endosc 2009; 70: 344-349

[98] Desomer L, Tutticci N, Tate DJ et al. A standardized imaging protocol is accurate in detecting recurrence after EMR. Gastrointest Endosc 2017; 85: 518-526
[99] Kandel P, Brand EC, Pelt J et al. Endoscopic scar assessment after colorectal endoscopic mucosal resection scars: when is biopsy necessary (EMR Scar Assessment Project for Endoscope (ESCAPE) trial). Gut 2019; 68: 1633-1641

[100] Bisschops R, East JE, Hassan C et al. Advanced imaging for detection and differentiation of colorectal neoplasia: European Society of Gastrointestinal Endoscopy (ESGE) Guideline - Update 2019. Endoscopy 2019; 51: 1155-1179

[101] Gupta S, Jacobs ET, Baron JA et al. Risk stratification of individuals with low-risk colorectal adenomas using clinical characteristics: a pooled analysis. Gut 2017; 66: 446-453

[102] Moon CM, Jung S-A, Eun CS et al. The effect of small or diminutive adenomas at baseline colonoscopy on the risk of developing metachronous advanced colorectal neoplasia: KASID multicenter study. Dig Liver Dis 2018; 50: 847-852

[103] Baik S], Park H, Park JJ et al. Advanced colonic neoplasia at follow-up colonoscopy according to risk components and adenoma location at index colonoscopy: a retrospective study of 1,974 asymptomatic Koreans. Gut Liver 2017; 11: 667-673

[104] Kim HG, Cho Y-S, Cha JM et al. Risk of metachronous neoplasia on surveillance colonoscopy in young patients with colorectal neoplasia. Gastrointest Endosc 2018; 87: 666-673

[105] Park CH, Kim NH, Park JH et al. Individualized colorectal cancer screening based on the clinical risk factors: beyond family history of colorectal cancer. Gastrointest Endosc 2018; 88: 128-135

[106] Park S-K, Yang H-J, Jung YS et al. Number of advanced adenomas on index colonoscopy: Important risk factor for metachronous advanced colorectal neoplasia. Dig Liver Dis 2018; 50: 568-572

[107] Kim NH, Jung YS, Lee MY et al. Risk of developing metachronous advanced colorectal neoplasia after polypectomy in patients with multiple diminutive or small adenomas. Am J Gastroenterol 2019; 114: $1657-1664$

[108] Kim NH, Jung YS, Park JH et al. Association between family history of colorectal cancer and the risk of metachronous colorectal neoplasia following polypectomy in patients aged $<50$ years. J Gastroenterol Hepatol 2019; 34: 383-389

[109] Jacobs ET, Gupta S, Baron JA et al. Family history of colorectal cancer in first-degree relatives and metachronous colorectal adenoma. Am J Gastroenterol 2018; 113: 899-905

[110] Saftoiu A, Hassan C, Areia M et al. Role of gastrointestinal endoscopy in the screening of digestive tract cancers in Europe: European Society of Gastrointestinal Endoscopy (ESGE) Position Statement. Endoscopy 2020; 52: 293-304

[111] Atkin W, Cross AJ, Kralj-Hans I et al. Faecal immunochemical tests versus colonoscopy for post-polypectomy surveillance: an accuracy, acceptability and economic study. Health Technol Assess 2019; 23: $1-84$

[112] Kim NH, Jung YS, Lim JW et al. Yield of repeat colonoscopy in asymptomatic individuals with a positive fecal immunochemical test and recent colonoscopy. Gastrointest Endosc 2019; 89: 1037-1043

[113] Adelstein B-A, Macaskill P, Turner RM et al. The value of age and medical history for predicting colorectal cancer and adenomas in people referred for colonoscopy. BMC Gastroenterol 2011; 11: 97doi:10.1186/1471-230X-11-97

[114] Fernández-Bañares F, Clèries R, Boadas J et al. Prediction of advanced colonic neoplasm in symptomatic patients: a scoring system to prioritize colonoscopy (COLONOFIT study). BMC Cancer 2019; 19: 734doi:10.1186/s12885-019-5926-4

[115] National Institute for Health and Care Excellence (NICE). Quantitative faecal immunochemical tests to guide referral for colorectal cancer in primary care. 2017: Accessed: Oct 2 2019: https://www. nice.org.uk/guidance/dg30 